\title{
Field-Portable Nano-Imaging: A New Tool for On-Demand Microscopy
}

\author{
Christopher S. Own, Matthew F. Murfitt, Lawrence S. Own \\ Voxa, Seattle, WA USA
}

Electron microscopy is widely regarded as a high-end laboratory science tool, where substantial resources are pooled to collect image data of exquisite quality. Electron microscopes (EM's) are uniquely able to produce detailed structural images that support discoveries from basic science to monitoring of industrial process. The strong scattering, large depth of focus, and unique blend of signals including elemental analysis are attractive in many applications. Being difficult to operate relative to many other common laboratory tools, EM's are traditionally housed in centers at universities and large research institutions where ample laboratory space, support staff, supplies, and skilled operators come together, or at industrial sites for organizations with research or quality control needs that justify the substantial cost. For those who do not have access to an on-site EM, many larger institutions and service centers accept samples sent in to be imaged, at great expense and often delay of weeks to months for complex analyses. The complexity, high cost, and significant maintenance associated with collecting EM image data has until now severely limited the fields in which EM can be realistically used [1]. This is exemplified in the number of EM instruments deployed (in the tens of thousands) to the number of deployed light microscopes (in the hundreds of millions) [2].

A new, smaller, more reliable and user-friendly personal EM -- the Mochii ${ }^{\mathrm{TM}}$ scanning electron microscope -has been developed by us at Voxa in Seattle, WA (Fig. 1). This low voltage microscope has features that bring accessible and on-demand EM imaging into fields and laboratories where EM was previously hindered by form factor, complexity, and cost. Among these features are small size and light weight $(0.25 \mathrm{~m}$ tall, light enough to carry in a suitcase); user-friendly native wireless tablet interface; multi- and distance-user capabilities (connection to unlimited client nodes), exceedingly low power consumption (by virtue of lowpower magnetic-electrostatic optics), and an integrated metal evaporator for easy sample preparation (only one pump-down cycle to image). We expect the cost to own and operate a Mochii ${ }^{\mathrm{TM}}$ microscope to be a fraction of the cost of typical EM's with similar imaging performance due to its low power consumption, simple design, and commoditized user-replaceable consumables.

The improved tablet interface and reduced cost compared to existing benchtop systems significantly lowers the barrier of entry to EM imaging in fields where money, space, and/or operational expertise were limited. Learners and scientists in schools and community science centers can begin using EM imaging to explore scientific phenomena at below light-diffraction-limit resolutions for the first time (Fig. 2). We also expect that smaller research labs and new labs or startup companies can easily begin accessing image data without the enormous investment that would be required for a typical EM.

Novel miniaturization features also open up access to EM imaging in scientific fields where samples would normally have to be stored and brought back from field work. With its exceedingly low power consumption, the Mochii ${ }^{\mathrm{TM}}$ can be operated in the field without AC power or a generator. Field forensic scientists can examine bullet casings, burn fragments, and other evidence on-site; shipboard oceanographers can examine flora in water samples while at sea (Fig. 3); and soil scientists can examine samples without packaging and shipping the samples (Fig. 4), thereby avoiding loss of critical structural data due to morphology changes during transit. Further, the Mochii ${ }^{\mathrm{T}}$ microscope's remote viewing and operation capabilities allow field scientists to collaborate instantly with colleagues around the world, as remote viewing systems in radiology have permitted radiologists to do for over two decades [3]. 
At the meeting, we will present images collected using Mochii ${ }^{\mathrm{TM}}$ under a variety of conditions, including images collected in the field, images collected by novice users, and images collected by remote operators. The additional use cases afforded by Mochii ${ }^{\mathrm{TM}}{ }^{\mathrm{s}} \mathrm{s}$ unique feature set represent a significant paradigm shift in microscopy instrumentation, taking the microscope out of the lab and into new environments, and opening high resolution high contrast imaging of to a wider audience and therefore broadening both scientific and citizen access to scientific phenomena at the microscale [4].

\section{References:}

[1] Stahlberg H \& Walz T, ACS Chemical Biology 3 (2008), p. 268-281.

[2] Grand View Research, Microscopes Market Analysis (2014).

[3] Thrall J, Radiology 243 (2007), p. 613-617.

[4] This work was supported by Voxa.

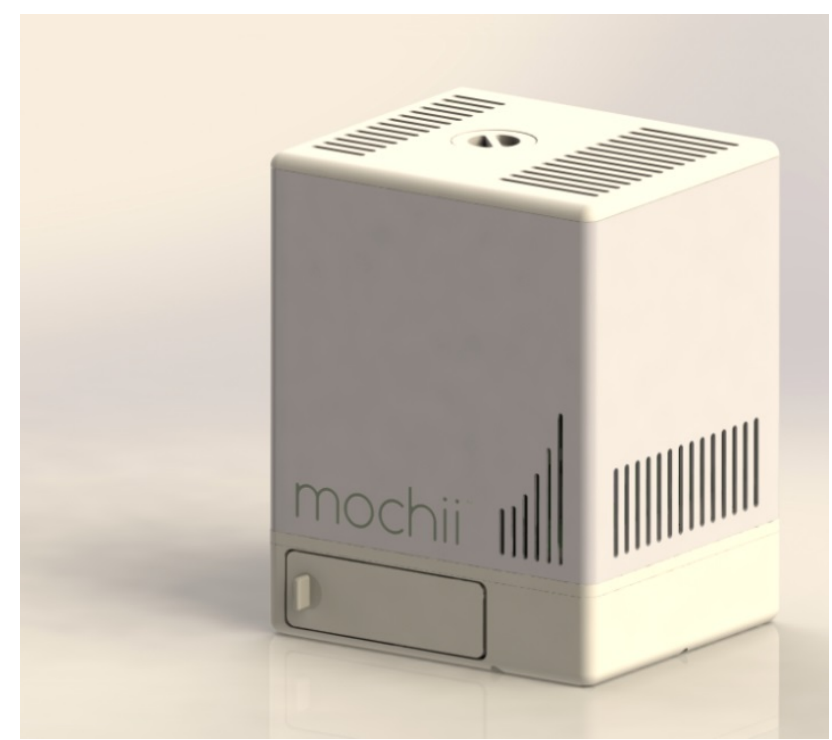

Figure 1. Mochii ${ }^{\mathrm{TM}}$ field-portable personal electron microscope

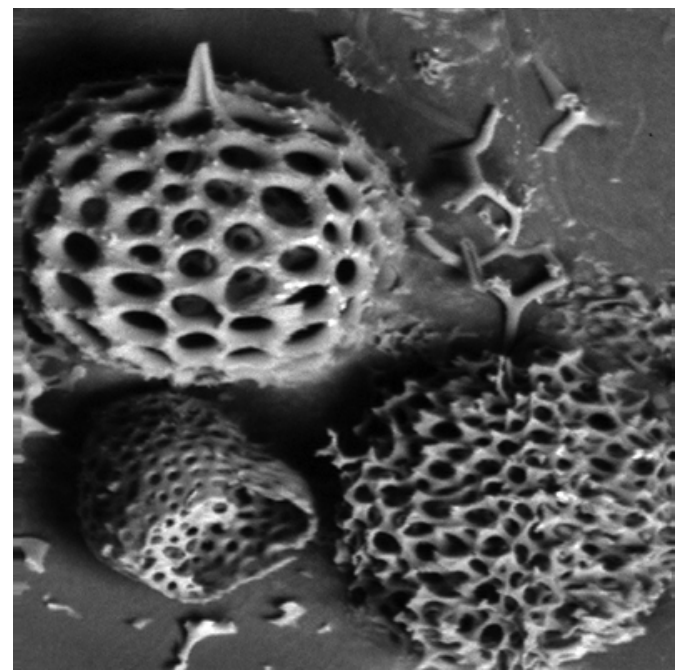

Figure 3. Holocene-era radiolaria collected from Sicily.

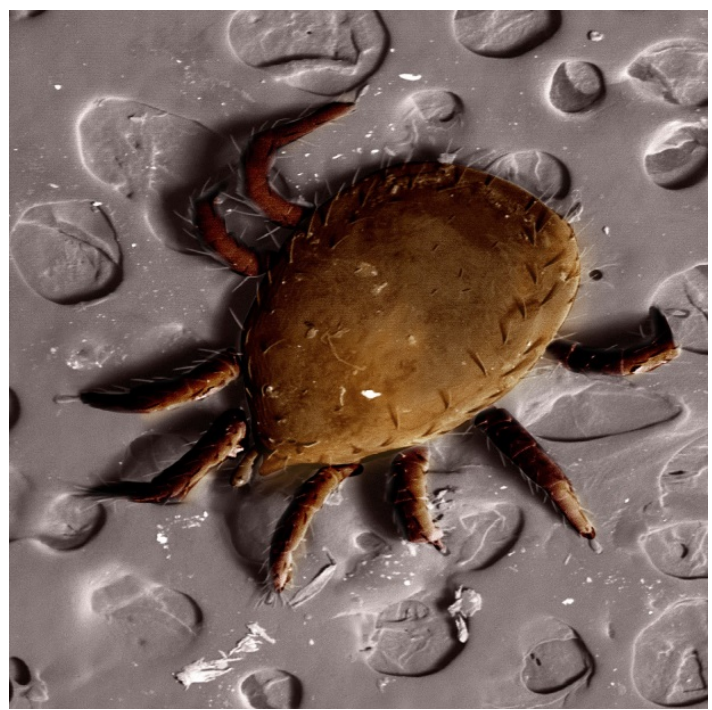

Figure 2. Androlaelaps schaeferi, a tiny mite species that populates Madagascar hissing cockroaches, a common household pet.

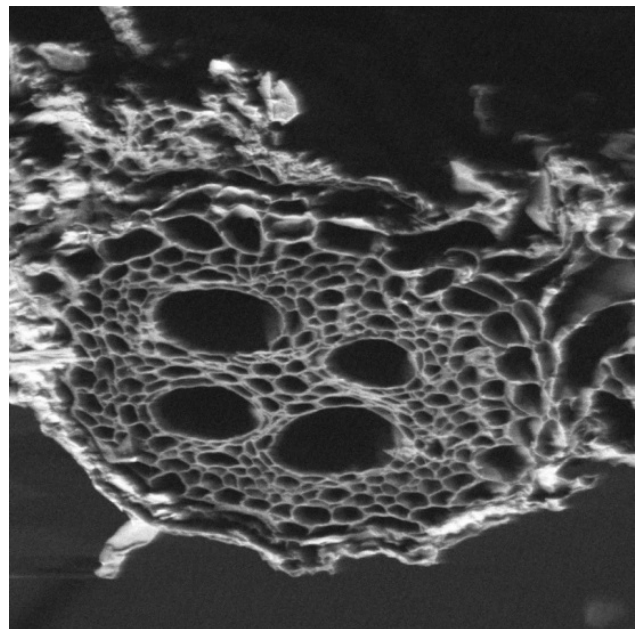

Figure 4. Cross section of root of vetiver grass, a grass with high holding power that, when planted, can reduce soil erosion in loose soils. 